perceptual factors affecting symbolic coding presentations on displays. One trusts that the evolution of electronic character generation techniques may help here by providing a better range of unambiguous symbols. The question as to what is the optimum form of display for data from a surveillance radar is fundamental, and it is encouraging to find here a detailed treatment of experiments to evaluate the relative detectability of signals with two different types of plan position indicator and a $B$ scope. Additionally, a valuable point is raised at the end of the chapter when it is said that virtually nothing is known about the effects of team behaviour on detection and tracking performance. This may be regarded by some as the biggest single factor in determining the performance of a manual extraction system.

There is a most comprehensive treatment of the factors affecting visual estimation of range and bearing, and this is followed by an examination of aids to accuracy in reporting these. It is perhaps to be expected that information available on the performance of relatively modern aids, for example, joystick, rolling ball and pencil indicator, is limited, but enough is said to give an indication of capability. One would like to see something more on the subject of manual versus aided-manual tracking since these concepts play a key part in modern systems where target information must be extracted and stored.

The concluding chapter has the meaningful title "The Operator as a Monitor". The effects on the vigilance decrement of environmental, observation and task factors are discussed and the chapter ends with a plea for more attention to be directed to the monitoring of the overall radar system performance, that is, both man and machine. This is a very real question and one which is only likely to be adequately solved with the evolution of suitable simulators which can record and analyse operator performance under operational conditions. Several hundred references are given in the appendix, a factor which considerably adds to the value of this book.

In the preface, the author indicates that he has not attempted a critical review and that the reader is left to refer to the original papers for a comparative interpretation. One is left to ponder whether that was the best course or whether a critical discourse would not have increased the authority of the work, still leaving the reader with the option of referring back. However, there is no doubt that this book does represent a valuable summary of the diverse information which exists on the man/radar display problem.

C. C. Fifuding

\section{HOW DOES THE BRAIN FUNCTION?}

International Review of Neurobiology

Vol. 4. Edited by Carl C. Pfeiffer and John R. Smythies. Pp. xi +388 . (New York: Academic Press, Inc.; London: Academic Press, Inc. (London), Ltd., 1962.) $86 s$.

$\mathrm{O}$ NCE again the editors of the International Review of Neurobiology have presented their public with a further volume, which follows the general pattern of earlier ones. There are seven reviews, each on some specific subject, two being in the field of neurophysiology, two in biochemistry and three related to pharmacology; yet all tend to be orientated to psychiatric and psychological aspects of function of the nervous system. Each of the authors is a well-known authority in his own field.

To summarize the chapters briefly is difficult, but a few words on each is essential for an adequate appreciation of this valuable book. The first review by Dr. Sidney Ochs deals with the nature of what Leão has described as spreading depression, which in the cerebral cortex is fascinating because of the slowness of its spread. The nature, form and reasons for spreading depression are ably described, and even I had to finish the chapter at one reading. It is concluded that spreading depression is neuronal, and that apical dendrites are involved. It is suggested that the characteristic change is an associated electrolyte change both into and out of the cells. The application of the use of spreading depression as a tool in various psychological investigations is discussed.

Dr. W. P. Koella next discusses questions of motor organizations especially at the subcortical level. This involves body movements after stimulation of the diencephalon, the cerebellum and the tectum of the midbrain. There are a considerable number of references to the works of Hess and Hassler, as well as to the author's own findings. This is a valuable and profound review which should prove extremely useful to those interested. in various types of movements especially of an involuntary type.

The development of the brain in the neonatal period especially from a biochemical and neurophysiological aspect is well described by Dr. Williamina Himwich. The chief purpose of this review is not so much to list the changes that occur at this period of life, but to make a comparison between those found in man and those in lower animals. In general the maturation of the human brain is greater at birth than in lower animals but after birth further development is slower than in most other species. There are some most useful charts relating to the times of cell proliferation and growth, and to myelination for the various species. A polypeptide (substance $\mathrm{P}$ or SP), detected more than 30 years ago by Von Euler and Gaddum, and its physiological significance are described by Drs. Lembeck and Zetler. SP is present in the nervous system and in the intestinal tract as a definite polypeptide, although it may be released from active precursors. It is related to function and is located in nerve cells, but may be reduced after nerve degeneration. It is not possible, despite the nature of its physiological activity, to state that it is a central transmitter substance. Methods of estimations and purification are discussed.

The next three reviews all relate to various pharmacological aspects such as psychotomimetic agents of an anticholinergic nature by Drs. Abood and Biel, who describe in particular the action of piperidyl glycolates. These substances act on brain mitochondria, increasing phospholipid turnover and membrane permeability, and are anticholinergic to smooth muscle. There are altered electroencephalogram findings in the intact nervous system. The possible mechanisms by which these actions are obtained are discussed as well as certain psychological studies in man. Drs. Pletscher, Brossi and Gey have produced a very excellent review on some benzoquinolizine compounds or derivatives and their relationship to monamine decrease, quoting much of their own work. The chemistry of the compounds is detailed and excellent, together with the result of experiments relating to their metabolic activities especially concerning the reduction of the monamine content in the brain. Various pharmacological actions on the nervous system, the gastrointestinal tract and the cardiovascular system are mentioned, especially in comparison with the action of reserpine. Lastly, Dr. Hoffer expands on his views on adrenochrome and adrenolutin in relation to psychology in man. He describes many of his experiments in man following the results that had been obtained in various other species. He discusses the possible mode of action of adrenochrome as well as the various behavioural changes found after its use, which he likens to the changes found in schizophrenia. He claims that there are no reported failures to corroborate his findings.

This volume lives up to the reputation already gained. by the three previous ones and can be read with considerable profit by all those in disciplines which are connected with the function and activity of the nervous system. Extremely few errors appear to have crept in whether of fact or in proof reading and the editors are to be congratulated.
J. N. Cumings 